Editorial

\title{
Where the Future is Being Made Today
}

\author{
${ }^{1}$ Mark A. Brown, ${ }^{2}$ Joachim Storsberg and ${ }^{2,3}$ Christian Schmidt \\ ${ }^{I}$ Department of Clinical Sciences, Colorado State University, Fort Collins, CO 80523-1052, USA \\ ${ }^{2}$ Fraunhofer Institute for Applied Polymer Research (IAP), Division of Life Science and Bioprocesses, \\ Department of Polymers for Biomedical, Engineering, Geiselbergstraße 69, 14476 Potsdam-Golm, Germany \\ ${ }^{3}$ Editorial Office, The American Journal of Immunology, S-207, 244, 5th Avenue, \\ New York, NY, 10001 USA and S-71, 1A, 400, King William St, Adelaide, SA 5000, Australia
}

Article history

Received: 21-06-2016

Revised: 27-06-2016

Accepted: 27-06-2016

Corresponding Author: Christian Schmidt Fraunhofer Institute for Applied Polymer Research, Potsdam, Germany, The American Journal of Immunology, New York, USA and Adelaide, SA, Australia Email: schmidt102@gmail.com

\begin{abstract}
Immunology is a fascinating discipline. Developmental biologists, molecular biochemists and clinicians, to name a few, work hard to resolve fascinating problems with direct connection to applied science. One of them being the determination of the developmental stage of a given cell. This may sound deceptively simple. Relevant questions include how commitment to a given lineage is maintained and whether a developmental stage can be described reasonably well using existing markers. Another area of hot debate is how immune cells interact with the nervous system and modulate pain sensitivity, such as chronic or acute pain. All of those topics and much, much more, are subject to intense investigation and debate in community journals. Here, we wish to present the American Journal of Immunology as another member of the family of Open Access journals in the field.
\end{abstract}

Keywords: Immunology, Policy
Growing up, I was fascinated by The Muppet Show and the adventures of Dr. Bunsen Honeydew and his assistant Beaker. Apparently, my feelings were not unique because Muppet characters are used to ease tensions associated with education about clinical interventions (Ramsay, 2014; Rohn, 2007). Yet the opening phrase 'Where the future is being made today' has, in my opinion, summed up my enthusiasm for science over the years, despite all the setbacks and the nearly Herculean task of sticking with a problem until one establishes at least a statistical trend, if not even a significant observation, that others can repeat and build upon, bit by bit.

As I matured in science, I also learned the joys of getting papers published after exhausting rounds of revision. Spending endless hours hunched over a paper and casting phrases that fit with the data obtained, the joy of writing a beautifully crafted paragraph and seeing less and less criticism of my writing nourished my confidence and enforced the time-old wisdom that good writing is an iterative process (Temple, 2013). With every text written over the years, the notion of sins by omission and the significance of properly referencing background to enable an assessment of progress made when it was actually made became clear and led me to write editorials to announce my views, e.g., Schmidt and
Brown (2015a; 2015b), Storsberg and Schmidt (2015) and Naqvi et al. (2008).

Very few people doubt the notion that free access to scholarly information (more commonly referred to as Open Access) provides an open forum to discuss scientific progress and provides a citation advantage (Eysenbach, 2006; Mathur et al., 2006). Questions relating to the viability of the Open Access publishing models are addressed, albeit not with a long-term perspective, by the documented growth of articles published under various forms of Open Access models (Laakso et al., 2011).

The above-stated argument of an open forum also addresses the question of how flawed peer-review is much easier to trace if the paper in question is available for free (Bohannon, 2013). This, however, does not address the validity of the notion that prestigious journals publish only prestigious material (Powell, 2016).

Appreciating this point, one can, however, argue that if published evidence is hidden behind a subscription wall, the paper can be easily overlooked if the full text is, for the sake of an argument, not readily accessible to search engines (Campanario, 2009). Credence for this notion that overlooked sources may contribute to an incomplete referencing of state of the art is provided by Sawin and Robinson (2016). While this does not 
address the question of 'finding the good stuff' (Powell, 2016), having published record not accessible to search engine increases the risk of fellow scholars committing 'sins of omission' due to lack of access to published record. Refer to Schmidt and Brown (2015a) for elaborations on this subject.

Now, where does The American Journal of Immunology fit in here? For one, this journal operates under the Open Access model (Pinfield et al., 2015), where authors are free to archive the published article with their institutional repository. Furthermore, the journal's editorial team is pursuing coverage by PubMed Central and Google Scholar to not only increase visibility but to communicate to the scholarly community our commitment to excellence and scholarly rigor.

As case in point, we are referring to the debate as to whether usage of clinical trial data obtained from patients unfit to consent to the validity of a study and, more importantly, to declare their willingness to participate in such studies to their own benefit or to the benefit of a larger group of individuals. Gauthier et al. (2016), Palm et al. (2016), Leonard and Myint (2006) and references therein as a guide for further reading. Neither side, opponents or proponents of such studies, questions the ethical dilemma constituted by such or similar situations.

To debate this issue in newspapers and talk shows is, in our opinion, not the prime choice of venues for such emotionally charged debates. In referring the exchange of arguments to written opinions in Open Access Journals, the public can access the debate via reasoned arguments and lines of reasoning presented from both sides, very much similar to the advantage of adversarial presentation of a case to a Grand Jury or Justices. In taking up this venerated method of providing the public with well-reasoned and written arguments from both sides, providing more nuanced lines of reasoning than sweeping charges, such as regarding patients unfit to declare informed consent are regarded as less valuable citizen to be subjected to demand of the argument that "benefits the majority or even the very patients themselves" or that "the need of the few outweigh the needs of the many" by way of respecting individual's life and integrity, one may see the benefits of such exchange for the specialist and general public and the whole scientific enterprise alike.

Again, we are not siding with either side in this debate. In pointing out the benefits of a written record, accessible to everyone via Open Access Journals, we might be able to avoid 'limited review' and 'sins of omission' (Schmidt and Brown, 2015a) to the detriment of people and, of even higher significance, our values of a civilized world where we weigh benefits and risks by adhering to law, civility and reasoned exchange for the betterment of us all.
With this, we cordially invite editors and the community as a whole to use the benefits of this Open Access Venue to debate issues of great importance. For this, we return to the beginning: "Where the future is being made today.' Let us strive to be inspired by this timeless phrase to making The American Journal of Immunology a vibrant forum for the exchange of ideas and concepts for the benefit of the life sciences community and beyond.

\section{Author's Contributions}

Mark A. Brown: Provided critical input and assisted in revising an inproving the paper.

Joachim Storsberg: Provided critical input and assisted in revising an improving the paper.

Christian Schmidt: Wrote the first draft of the paper and provided critical input and assisted in revising and improving the paper.

\section{Ethics}

MAB, JS and CS report no conflicts of interest with regard to this report. MAB and CS are members of the Editorial Board of The American Journal of Immunology and are waived from the Article Processing fee for this contribution; $\mathrm{MAB}$ and $\mathrm{CS}$ receive no remuneration, either individually or collectively, for their editorial work.

\section{References}

Bohannon, J., 2013. Who's afraid of peer review. Science, 342: 60-65.

DOI: $10.1126 /$ science. 342.6154 .60

Campanario, J., 2009. Rejecting and resisting Nobel class discoveries: Accounts by Nobel Laureates. Scientometrics, 81: 549-65.

DOI: $10.1007 / \mathrm{s} 11192-008-2141-5$

Eysenbach, G., 2006. Citation advantage of open access articles. PLoS Biol., 4: e157- e157. DOI: 10.1371 /journal.pbio.0040157

Gauthier, S., P. Rosa-Neto and J.S. KassS, 2016. Ethical considerations for the use of next-generation alzheimer drugs in symptomatic and at-risk patients. CONTINUUM: Lifelong Learn. Neurol., 22: 615-8. DOI: 10.1212/CON.0000000000000306

Laakso, M., P. Welling, H. Bukvova, L. Nyman and B.C. Björk et al., 2011. The development of open access journal publishing from 1993 to 2009. PLoS One, 6: e20961-e20961.

DOI: 10.1371/journal.pone.0020961

Leonard, B.E. and A. Myint, 2006. Changes in the immune system in depression and dementia: Causal or coincidental effects? Dialogues Clin. Neurosci., 8: 163-74. PMID: 16889103 
Mathur, S., C. Schmidt, C. Das and P.W. Tucker, 2006. Open access and beyond. Mol. Cancer, 5: 35. DOI: 10.1186/1476-4598-5-35

Naqvi, H.R., S. Mathur, D. Covarrubias, J.A. Curcio and C. Schmidt, 2008. The problem of choice. Mol. Cancer, 7: 86. DOI: 10.1186/1476-4598-7-86

Palm, R., S. Jünger, S. Reuther, C.G. Schwab and M.N. Dichter et al., 2016. People with dementia in nursing home research: A methodological review of the definition and identification of the study population. BMC Geriatr., 16: 78-78. DOI: $10.1186 / \mathrm{s} 12877-016-0249-7$

Pinfield, S., J. Salter and B.A. Bath, 2015. The "total cost of publication" in a hybrid open-access environment: Institutional approaches to funding journal article-processing charges in combination with subscriptions. J. Assoc. Inform. Sci. Technol., 67: 1751-1766. DOI: 10.1002/asi.23446

Powell, K., 2016. Does it take too long to publish research? Nature, 530: 148-51. DOI: $10.1038 / 530148 \mathrm{a}$

Ramsay, C., 2014. It's not the Muppet show, it's a unique approach to medical education.
Rohn, J., 2007. Science and society: Why aren't white coats sexy? The Biochemist, 35: 28-30.

Sawin, V.I. and K.A. Robinson, 2016. Biased and inadequate citation of prior research in reports of cardiovascular trials is a continuing source of waste in research. J. Clin. Epidemiol., 69: 174-178. DOI: $10.1016 /$ j.jclinepi.2015.03.026

Schmidt, C. and M.A. Brown, 2015a. The sins of omission. J. Clin. Exp. Oncol., 4: 1-1. DOI: $10.4172 / 2324-9110.1000 \mathrm{e} 109$

Schmidt, C. and M. Brown, 2015b. Relating the pendulum of democracy with oncology research. J. Clin. Exp. Oncol., 4: 3-3. DOI: $10.4172 / 2324-9110.1000 \mathrm{e} 110$

Storsberg, J. and C. Schmidt, 2015. The risk associated with corneal transplantation from donors with cancer: Worth the gamble? J. Cancer Epidemiol. Treat., 1: 1-1.

Temple, E., 2013. 'My pencils outlast their erasers': Great writers on the art of revision. 